\title{
PODCASTING AND PERSONAL BRANDS: MAPPING A THEORETICAL PATH FROM PARTICIPATORY EMPOWERMENT TO INDIVIDUAL PERSONA CONSTRUCTION
}

\author{
TIMOTHY YEE
}

\begin{abstract}
This research paper critically analyses The Osher Günsberg Podcast to illustrate a theoretical disconnect between early participatory media theories and the contemporary practice of using the podcast to construct a networked branded persona. I trace the history of early theorisations of the medium, first regarded by leading scholars as a tool for user empowerment in the 'participatory turn' in media studies before examining how it is employed by conventional media personalities to establish transmedia personal brands; a particular phenomenon emerging at the forefront of a renewed interest in podcasting by traditional media stakeholders. I argue that this disconnect reveals a need for scholars who study the podcast to now draw on the emerging field of persona studies, which offers a range of new tools that will be useful in analysing the continued evolution of podcasting under its new market pressures and potentials.
\end{abstract}

\section{KEY WORDS}

Podcasting; Participatory Media; Personal Brands

\section{INTRODUCTION - Established Players EnTERING A New MARKET}

In August, 2016, I attended the Australian Broadcasting Corporation's OzPod 2016, Australia's very first media industry conference exclusively dedicated to podcasting. The event explored "everything from audience acquisition and retention, approaches to measurement, new technologies, the rise of the podcast in traditional media, revenue opportunities and the art of storytelling" (ABC 2016a) through a program of panel discussions and keynote presentations. This was an ambitious agenda for a one-day conference, but that so much was crammed into such a short period of time reflected the fact that podcasting had been paid far less attention than other new media formats such as blogging, social media or online video streaming. Following in the wake of a rapid growth in podcasting worldwide, this business-focused schedule seemed understandable. The underlying implication was that there is much work to be done if podcasting was going to be taken seriously by the media industry, its advertisers and broader Australian audiences.

Globally, the Apple Podcast app served up over 10 billion streaming plays in 2016 across 155 countries, up from 8 billion in 2014. According to the company's Podcast Business Manager James 0. Boggs, podcasting has three established business models: "ads and sponsorship, community support/donation and upsell," each which are key for creative and financial success 
(Boggs 2017). Third-party research commissioned by a group of prominent podcasting businesses including Gimlet Media and Midroll Media suggests that the "podcasting industry" is now on track to generate more than $\$ 659$ million in annual revenue by 2020 in the USA alone (Price Waterhouse Coopers 2018). In Australia, initial research for OzPod 2016 showed there had been a 14 per cent net increase in podcast listening year on year, with 36 per cent of people listening to a greater variety of podcasts compared to the year before (ABC 2016b).

All of this development and excitement around the podcast hints at the fact that it is no longer adequate to consider the media format as just remediated radio or questionable-quality audio produced by amateurs existing in non-commercial environments (McHugh 2016, p. 7077). Instead, podcasting is undergoing a maturing process that requires media scholars to more closely examine the podcast and its nuanced developing cultures.

This research paper specifically investigates the way that Australian media personalities use podcasting to add a sense of intimacy to their already-established personal brands, as a particular phenomenon emerging at the forefront of this new interest in podcasting as a serious media channel. To do this I offer a brief history of early theorisations of podcasting, first regarded by leading scholars as a tool for user empowerment in the 'participatory turn' (Jenkins 2014, p. 271) in media studies. This is followed by an examination of how the involvement of traditional media brands such as This American Life have altered the podcasting landscape, pushing professionally produced shows such as Serial into the cultural mainstream. A critical analysis of popular Australian podcast, The Osher Günsberg Podcast, proceeds to illustrate how traditional media personalities are using the format to construct nuanced transmedia personal brands that straddle both participatory and commercial environments through the medium's intimate affordances. I draw on the emerging field of persona studies to describe the nuances of this phenomenon which are not widely accounted for in existing podcast studies literature. In doing so it is argued that media scholars studying the podcast must move beyond popular ideas of collective user empowerment and draw on the range of new theories and tools that place persona construction at the centre of participatory media studies and practices.

\section{METHODOLOGICAL APPROACH}

To conduct this research, I have performed a close critical reading of a high profile Australian podcast, The Osher Günsberg Podcast. I created an archive of approximately eight hours of audio content with the selection of episodes I studied all published in the Apple Podcasts App within the previous 24 months at the time of listening. By performing a close critical reading I have been able to interpret these podcast episodes as cultural artefacts using a range of theories from discourses including participatory media studies, affect theory and persona studies to better understand how participatory media cultures are evolving. As McKee explains, "We interpret texts (films, television programmes, magazines, advertisements, clothes, graffiti, and so on) in order to try and obtain a sense of the ways in which, in particular cultures at particular times, people make sense of the world around them" (McKee 2003, p. 1).

I listened to each podcast episode in line with Glaser and Straus' inductive grounded theory approach, that is, an intensive rather than extensive research approach (Harré 1979, p. 137) concerned with processes instead of patterns (Sayer 1992, p. 242-244 cited in Hesmondhalgh and Baker 2010, p. 15). Additionally, "Glaser and Straus (1967) argued that theories developed using their model will be understandable by practitioners, and will 'work' in real world settings" (Oktay 2012, p. 5). 


\section{Grassroots Beginnings: a brief history of podcasting and its potentials}

On February 12, 2004, The Guardian published an article titled 'Audible revolution' written by Ben Hammersley, a British journalist, internet technologist, blogger and broadcaster. Hammersley claimed that the increasing flow of communication between journalists and their readers, the decentralisation of networked distribution and the emergence of new business models for the online marketplace were leading the media landscape to a "boom in amateur radio". This exciting medium was so new at the time that Hammersely didn't even have the adequate terminology to categorise what he was reporting at the intersection of iPods, cheap audio software and the rise of weblogs. "But what to call it? Audioblogging? Podcasting? GuerillaMedia?" he wrote (Hammersley 2004).

Across broader networked environments other groundbreaking new media experiences were transpiring. That same year, Mark Zuckerberg made Facebook available to students at Harvard University; in 2005, the video sharing platform YouTube was founded; in 2006, TIME magazine proclaimed "You" the person of the year; and in 2007, Apple launched the first ever iPhone. Just one month after Hammersley first used the term "podcasting" (Berry 2006, p. 143, Madsen 2009, p. 1192), Henry Jenkins published an article in The International Journal of Cultural Studies that attempted to map such shifts in the media into "a theory of media convergence that allows us to identify major sites of tension and transition shaping the media environment for the coming decade" (Jenkins 2004, p.33). Clearly, both media practice and media theory were undergoing a period of incredible change. Moreover, it appeared that the podcast was an important component of this movement, embodying a sense of empowerment experienced by new media users.

Early theorisations of podcasting comfortably placed the medium within what Jenkins had previously referred to as 'participatory culture'. These are cultures in which individuals feel encouraged to express and share ideas, where knowledge is transferred from experienced members to new members, contributions are seen to matter, social relationships are meaningful, and most individuals are able to participate due to low barriers of entry (Jenkins et al. 2009). In Jenkins' ethnography of Star Trek fans, he adapted de Certeau's (1984) concepts of 'poaching' and 'tactics' to demonstrate how television fans could be understood to be active and empowered agents who made meaning through mediated communities and derivative work they were creating as 'Trekkers' (Jenkins, 1992). This work called on traditional media organisations to reconsider the idea that "all participation in the consumer economy constitutes cooptation" (Jenkins 2004, p. 36). Recasting fans as participants in the development of a media franchise instead of simply consumers set the groundwork for his theories on participation in a convergent media environment. He canvassed his perspectives in his article 'The cultural logic of media convergence' (2004), and then expanded these theories in Convergence Culture: where old and new media collide (2006a) and Fans, Bloggers, and Gamers: exploring participatory culture (2006b). A key pillar of this effort to extend the conclusions in Textual Poachers (Jenkins 1992) was the work of Pierre Lévy (1997), which provided an explanation of how empowering practices of participatory fandom could evolve alongside networked technologies.

Lévy's idea of 'collective intelligence' articulated Jenkins' theory that media fans were increasingly empowered by the rise of digital networks and as a result were able to access knowledge and power that far exceeded their own individual limitations. Speaking on Lévy's concept Jenkins says, "And this organization of audiences into what Lévy calls knowledge communities allows them to exert a greater aggregate power in their negotiations with media producers" (Jenkins 2006a, p. 27). 
This signaled a 'participatory turn' in media studies (Jenkins 2014, p. 271) which asserted that a new conceptualisation of the media consumer as participant occurred at the intersection of new technologies that enabled consumers to remix and recontextualise content, expanding cultures of Do-It-Yourself (DIY) media production and economic trends that encouraged the flow of information across different platforms (Jenkins, 2006b, p. 135-136). This thinking expanded the concepts of the 'prosumer' (Toffler, 1980) and the 'pro-am' (Leadbeater and Miller 2004), themselves more recently contemporised by Axel Bruns' idea of the 'produser' (Bruns 2008). Such cultures were open to willing contributors, which disrupted the established dichotomy between artist and audience, producer and consumer (Jenkins 2006a).

According to Richard Berry, podcasting is an example of this way of conceiving media producers and consumers. Berry states, "What podcasting offers is a classic 'horizontal' media form: producers are consumers and consumers become producers and engage in conversations with each other" (Berry 2006, p. 146). The medium was identified as an early expression of DIY media in the digital era that allowed individuals to leverage the network to communicate with each other (Meserko 2015a, p. 798) and establish important new social connections (McClung and Johnson 2010, p. 85).

The podcast's nascent popularity was spurred on by a rising culture of 'music for free' which emerged from the prevalence of peer-to-peer sharing platforms and the ascent of the Apple iPod (Menduni 2007, p. 9). At the time, the iPod was redefining how listeners 'inhabited' the spaces they moved through in the everyday, creating "privatised audio bubbles" in which they could control "thoughts, feelings and observations as they manage both space and time" (Bull 2006, p. 344). The device's technological ability to port a vast library of audio files far exceeded what was possible with precursory personal music players such as the Sony Walkman and Discman, which relied on hardware. Through its integration with the iTunes software, the iPod enabled its owners to travel with a near limitless number of voices, songs and ideas, ready to be played at the click of a button. Through this non-linear listening capability, podcasting contributed to a new form of freedom in which audiences could time-shift their listening and avoid the same homogenous programming and saturated advertising found on traditional radio. It celebrated the new possibilities of fragmented media consumption (Crofts et al. 2005), aided by the medium's incorporation into the iTunes software in 2005 and later the introduction of a standalone Apple 'Podcasts' iPhone app in 2015 (Morris and Patterson 2015, p. 223).

But beyond illustrating new models of networked and mobile communication, podcasting was a tool of empowerment that placed the capabilities of media production into the hands of the non-professional audio producer. It enabled a type of "de-professionalised" (Luders 2008 cited in Bottomley 2015, p. 181) world-building that helped producers and consumers make sense of the hyper-mediated environments that increasingly surrounded them (MacDougall 2011, p. 718). For the first time, networked audiences could seamlessly listen to unconventional perspectives brought into public forums by the audio recordings of amateur content creators. Virginia Madsen draws attention to The Dawn and Drew Show! as an example of how early podcasting enabled audiences to connect with niche voices (Madsen 2009, p. 1196).

In 2004 Dawn Micelo and Drew Domkis started recording a podcast about "two exgutter punks who fall in love, buy a retired farm in Wisconsin (then move to Costa Rica and back) and tell the world their dirty secrets" (Micelo and Domkis 2017). At the time, the hosts were reflective of a new wave of alternative voices in the networked media landscape that did not rely on endorsement from traditional gatekeepers. Micelo commented on the success of their homegrown, self-produced amateur show in their 100th episode saying, "Who'd have 
thought anyone would listen?” “Take this, Big Brother! I don't need you. I don't need your fucking contracts. I've got my own radio show!" (Micelo as cited in Madsen 2009, p. 1196). Madsen says this is expressive of the early excitement that accompanied amateur podcasting and its ability to challenge traditional media and communication channels (Ibid).

What the podcast provided for Dawn and Drew and a raft of other early non-mediaprofessionals such as Dan Klass of The Bitterest Pill and Mignon Fogarty of Grammar Girl, was agency to independently connect with audiences. This kind of grassroots broadcasting posed a challenge for traditional media companies such as public broadcasters, which had long "promoted themselves as gatekeepers of quality content and journalistic integrity among the free-for-all babble of the internet" (Murray 2009, p. 199). Established media companies risked "brand dilution" as they navigated the bourgeoning days of the medium and its "interactive and participatory characteristics" (Ibid.) The DIY, user-generated podcast embodied the optimism and the potentials of participatory cultures in the early days of the web to redefine the media landscape beyond the influence of traditional media corporations.

\section{THE PodCAST's SECOND COMING: ATTENTION FROM BIG BRANDS AND BIG PERSONALITIES}

Despite the idealistic rhetoric of user empowerment marked by the participatory turn, columnist Kevin Roose wrote in New York Magazine that sometime in 2009 or 2010, the hype surrounding the early days of podcasting seemed to wither. Roose attributes a lack of content innovation as well as the rise of online music and video streaming as potential detractors, and claimed that only podcasting stalwarts such as This American Life and Radiolab (two remediated broadcast radio shows) remained prevalent in Apple's podcasting top charts. "Download numbers fell. Interest waned," he reported (Roose 2014). Yet just five years later in 2014 an entirely different problem had emerged - "There [were] too many great podcasts to keep up with" (Ibid., emphasis in original text). Independent podcasting networks such as Radiotopia had formed, podcasting production companies such as Pineapple Street Media were founded, and a number of ad buying companies such as Midroll Media were making ground in monetising content at scale. Consumers and producers alike heralded in a renewed podcasting boom. Roose speculated that an increase in audience awareness, higher quality production values, and the integration of smart phones into new cars were three significant factors contributing to this podcasting renaissance.

Richard Berry identifies the podcast Serial as a landmark that encapsulates this second coming. Serial's first season was released in 2014 and followed the 1999 true crime murder story of high-school student Hae Min Lee. Each week a new episode was delivered by RSS feed to subscribers as per the standard protocol for podcast distribution. However, unlike any other podcast that came before it, Serial achieved record-breaking success. It became the fastest podcast to reach five million downloads (Dredge 2014), it was still being downloaded 500,000 times per day months after its initial release (Kohjer 2015 cited in Berry 2015, p. 171), and it was the first podcast to attract an off-season ad campaign (Blattberg 2015), meaning that marketers were willing to pay to retro fit their advertisements into the show to capitalise on any downloads thereafter. It also spawned a number of podcasts about the show, a practice not common at the time (Ibid.).

In addition to the technological convergences Roose wrote of, Berry attributes Serial's success to its association with the "well-known, much loved and highly respected brand" This American Life (TAL). He unpacks how a new media brand forged by a traditional broadcast powerhouse gained traction in an environment that was originally celebrated by scholars and 
amateurs for its ability to subvert such media hierarchies. Berry notes that Serial was a spin-off of TAL with co-producer and host Sarah Koenig having worked on the former radio show for a number of years before starting her own podcast; TAL's anchor host Ira Glass is himself a wellregarded and highly visible media personality, who also appeared on popular television show The Tonight Show with Jimmy Fallon to promote Serial, including airing an instructional video telling viewers how to listen to Serial; and Glass also presented a preview of Serial via the TAL RSS feed (Berry, 2015).

Through all of this promotion, a Serial trailer had already reached the top spot on the Apple Podcast charts before the first episode's release. Furthermore, Berry's research discovered that more than half of survey respondents said that they were listeners of TAL before they listened to Serial (Berry 2015, p. 174). It was a show that was entering a market that had been primed by the success of highly produced independent shows such as $99 \%$ Invisible (Ibid.), but it had the cultural clout and marketing channels of one of American public radio's biggest entities. In other words, the podcast's renaissance and its entry into the pop-cultural zeitgeist wasn't only caused by the participatory potentials of new media exemplified by the efforts of amateur content creators such as Dawn and Drew, but also due to the profile of professional media brands such as This American Life.

The role that traditional media brands have played in the rise of podcasting is an important consideration for scholars studying how media participants use the podcast in the contemporary moment. Since 2014 many traditional media personalities have created their own podcasts, banking on their traditional media celebrity status similar to the way Serial leveraged the brand capital of TAL. In Australia, a selection of recognisable media stars from radio, television and print media have started their own independent podcasts. For example, the ABC's Leigh Sales and Annabel Crabb host Chat 10 Looks 3, a show offering insights into their lives as television hosts, journalists, mothers and friends; Triple J radio alumnus Tom Ballard hosts Like I'm a Six-Year-Old, an interview show featuring young political and social activists; former Cosmopolitan editor and founder of the Mamamia Women's Network Mia Freedman hosts a talk show called No Filter; and standup comedian Wil Anderson produces, hosts and cohosts a variety of shows about philosophy, sport and pop culture.

The turn to personal broadcasting by these media personalities reflects a shift in the rhetorical dimensions of podcasting; it's no longer exclusively the side hobby of DIY pundits, scifi fans or bedroom producers. It's now an important content channel for serious players in the Australian media landscape. To illustrate the emerging dynamic between this new culture of podcasting and traditional media brands I have performed a close critical reading of one of Australia's most popular shows, The Osher Günsberg Podcast (TOGP). Observing how wellknown media personalities use podcasting to reveal intimate aspects of themselves places the medium within the context of the contemporary practice of transmedia personal branding.

\section{Participating to construct an intimate personal brand: Reading The Osher Günsberg Podcast}

Despite a successful career in commercial Australian media that has spanned more than a decade and canvased stints in radio, television and live performance, Osher Günsberg hosts an independent podcast self-described in the Apple Podcasts app as "A weekly conversation with someone remarkable that will leave you truly inspired." By some measures, it is an Australian podcasting success story that celebrates what is possible when individuals invest in participatory media formats. It has an international audience of listeners (as comments in Apple iTunes reveal), over 800 mostly favourable reviews on the Apple Podcasts app, is, at the time of writing, ranked 17th in the corresponding comedy top charts, has a 5-star Apple listener rating, 
and boasts an archive of more than 170 past episodes recorded over more than four years. Günsberg states he produces the podcast in his spare room using off-the-shelf consumer technology (Please support the podcast $x$ 2016) allowing him to deliver content with ease (Tulley 2011, p. 268), free from the limitations of traditional radio (Fauteux 2015, p. 203). Günsberg alludes to his ability to connect with audiences and build an online community premised on developing a meaningful relationship with his listeners saying, "This show makes my week and I know from the emails that I get every single week that a lot of people enjoy it" (Please support the podcast $x$ 2016).

Günsberg's podcast is notably different to his show business work elsewhere where he is known for hosting popular reality television shows such as Australian Idol, The Bachelor, Bondi Rescue and So You Think You Can Dance (US). On TV screens his personality is confined by well-worn formats of novelty challenges, confession cams and contestant eliminations. The podcast, however, holds potentials in its intimate medium affordances which make it more conventional to talk about more personal anecdotes, perhaps unexpected of a high-profile media personality.

In this way TOGP can be immediately seen to operate within the transmedia personal brand of Osher Günsberg. This personal brand also consists of his roles as the host of primetime television shows and as co-host of the Stav, Abby \& Osher show on Hit105 Brisbane. In Convergence Culture: where old and new media collide (2006a), Jenkins outlines this kind of matrix with the concept of transmedia storytelling as a marketing strategy for brands. It is a storytelling technique that stems from the Japanese marketing strategy known as 'media mix' and refers to "a process where integral elements of a fiction get dispersed systematically across multiple delivery channels for the purpose of creating a unified and coordinated entertainment experience" (Jenkins 2007). He confirms the potential of transmedia brands saying, "close collaboration between program producers, brand gurus, and new media companies suggests rapid growth of industry interest in transmedia entertainment over just a few short years" (Jenkins 2006a, p. 125).

Though Jenkins is referring to massive fiction story world franchises such as The Matrix, elements of this framework appear prevalent in Günsberg's media participation, too. As a podcast host, television presenter and radio personality Günsberg is at an epicentre of Australia's creative industries and exposed to those same producers, brand marketers and media companies that converge in transmedia storytelling. Comparably, where Jenkins says transmedia stories reveal different dimensions across different channels, Günsberg is revealing different parts of his personality across different discourses. The outcome of participating in both commercial and self-produced media in this fashion is increased listener self-brand connection, which generates social and commercial authority (Granitz and Forman, 2015: 44). The crosspollination of the personal and professional is clear in a podcast episode where Günsberg asks listeners to tune-in to the 2016 season premiere of The Bachelor, which is "less than 72 hours away" (Ep 143: Socratis Otto 2016). He calls on his podcast listeners to watch because the TV show's stakeholders are "looking for a big opening," referring presumably to high numbers in audience viewership and ratings.

The outcome of Günsberg positioning himself as an accessible yet layered media personality is what Jenkins refers to as transmedia engagement (Jenkins, Ford \& Green 2013, p. 132). Transmedia engagement is concerned with prolonging interactions between media participant and media stimulus for a deeper, richer experience, (Ibid., p. 137). In the case of Osher Günsberg, audiences can discover the dynamics of his personal brand on their morning commute via his radio show, during their lunch break via the television and in bed before going 
to sleep via his podcast. The result is a nuanced personal brand that feels familiar to large populations across multiple settings, increasing the personality's exposure, status and social capital. It is a formula that works because the host benefits from having an existing audience. Within this matrix of media formats, the podcast operates as a contrast to other mediums, giving listeners a behind-the-scenes and seemingly intimate look into the host's personal life.

Meserko explains that positioning oneself between traditional and new media broadcasting technology is a strategic response to the increasing preoccupation that audiences have with 'technologies of self-fashioning,' (Johnson 2008, p. 32 in Meserko 2014, p. 458). These podcasts are examples of "overt commitment to self-improvement and self-fashioning [...] Such podcasts are lessening the distance between celebrities and their fans through discourses of therapy, self-improvement, and intense indulgences of feeling" (Ibid., p. 458). This can become an important routine practice for both podcaster and audience as Kris Markman notes that interpersonal connections are one of the main motivators for podcasters to continue podcasting. Markman says, "Listener emails, submissions, discussion fora, and phone calls (via voicemail playback) were used regularly, and the feedback podcasters received from these channels helped sustain their interest" (Markman 2011, p. 557). That is, the more of their personal life a podcaster is seen to reveal to their audience, the stronger that bond can become, and therefore, the more resonant the overarching transmedia persona may be.

This is a common conceit in the podcasting landscape as Meserko's research on the immensely successful US comedy podcast WTF with Marc Maron reveals. Meserko investigates how WTF's perceived authenticity - of its host comedian Marc Maron and his guests (having previously included former US President Barack Obama) - has contributed to the show's success. Meserko claims, "There is a perception that Maron's podcast allows him a space to be more real and reveal a more 'authentic' version of himself' (Meserko 2015b, p. 797). He adds that the podcast's affordances enable first-person accounts to explain away controversy, participate in communal reflection and provide a more authentic presentation of oneself (Ibid., p. 808). Furthermore, consider the closeness of the human voice as it penetrates a listener's private sound-world (Madsen and Potts 2010, p. 43), the mobility of human connection made possible by devices such as the iPhone (Crawford 2012, p. 214) and the practice of 'background listening' that is "critical to the sense of intimacy generated in these spaces; ongoing contact with the minutiae of a person's life" (Crawford 2009 cited in Crawford 2012, p. 68).

Siobhan McHugh notes that audio media can impact its creators and listeners in intense ways that draw on the 'affective power of sound' (McHugh 2012). McHugh locates the power of affect in audio in the emotional tenderness portrayed by the human voice. In a study on radio documentaries, she noted that "when an informant narrates an experience in an affecting way (i.e., with palpable emotion), listeners will register the emotion through the prism of their own lived experiences; we can infer that this personalization will confer added impact" (McHugh 2012, p. 195). The human voice can be used to emote empathy in listeners and place them in an intimate mediated relationship with the storyteller. For the podcast, the 'inbetween-ness' of affect (Gregg \& Seigworth 2010, p. 1) is constructed not just in moments of "affective auditory elements such as ambient sound and music" (McHugh 2012 p. 198), but also through additional medium affordances.

In their analyses of the Love + Radio and The Heart podcasts, Spinelli and Dann (2019) argue that the use of earbuds to listen to podcasts re-embody the networked voice when placed in contact with the listener, literally inside the body in most cases. While historically scholars have considered earbuds as tools to keep noise out by creating private sound bubbles, this emphasis highlights what they let in. Earbuds "allow for hyper-intimacy" that channel another 
human's voice directly into your mental space, "present inside you" (Spinelli \& Dann 2019 p. 84). In their fieldwork the researchers found that podcast hosts were sometimes aware of this physicality, and considered how tone, granularity and microphone proximity may be delivered within this context. They further suggest that this format intimacy - the "native podcasting approach" (Ibid. p. 87) - allows for podcasters to put various storytelling techniques to work in order to create empathy between podcast host, subject and listener. "[P]roducers brought about empathy very often through identity formation narratives, through a human seeking for belonging or searches for relationships that deliver a meaning or insight" (Ibid. p. 87).

Günsberg can be seen employing these native podcasting self-help narrative tropes in episode 143 when discussing his mental health:

I hope your week was good, I had some tough days this week. I'm not going to lie. It was difficult for a couple of days there. Yep, it was tough. It was tough on [Günsberg's fiancé] because she was worried about what was happening with me and I just had to explain: this is all it is, it's just a thing that plays in my brain. It's nowhere near as bad as it used to be thanks to the new meds, which are nice. But it's still there and it's always going to be there and I just have to get better and better at learning how to rationalise it and figure it all out. So, yeah, I did have some tough days this week... (Ep 143: Socratis Otto 2016)

Delivered physically via earbuds, in a tempered tone and without any novel sound track or effects, this snippet reflects the intense intimacy channeled into the medium. Through his podcast, Günsberg leverages these affordances, simultaneously contrasting and complementing his involvement in traditional media franchises, to champion a personal brand, premised on broadcasting 'real conversations between real people'. This 'realness' may or may not be performed, but it doesn't mean it is not perceived as authentic. While in other participatory media cultures, such as MP3 blogging, authenticity is perceived in part by distance from commercialisation (Borschke 2014), the podcast's native affordances and DIY history seem to assist even those from highly commercialised backgrounds in a kind of redemption; an opportunity to 'truly be themselves' despite whatever association with programming on corporate media networks they may have. This kind of affective, open, tell-all content is an example of the show's tagline in action: "Authenticity is the new black. Come and join us."

The phenomenon of traditional media personalities turning to the podcast to add depth and nuance to their existing personal brands through mediated authenticity and intimacy requires an advancing of the podcasting literature canon. While early participatory media theories from Jenkins et al. are useful to make sense of podcasting at the turn of the millennium, this study of The Osher Günsberg Podcast demonstrates its inadequacies in describing more contemporary trends. What the emergence of transmedia brands in this space tells media scholars is that - alongside building collective intelligence and creating grassroots fan communities - the construction of multifaceted persona is now a central tenet of participatory media cultures. For this, researchers studying podcasting may benefit from turning to the emerging field of persona studies.

\section{Potentials In PeRsona StUdies}

In David Marshall's work on persona he builds on early theorisations of the concept in psychoanalysis and philosophy, following on from the work of key scholars such as Jung, Goffman, Butler and Foucault (Barbour, Marshall \& Moore 2014, p. 2). Marshall describes persona as the strategic construction of forms of public identity and states that the concept is "not about the real 'self', but it [has] indices that link the individual to the persona" (Marshall 
2016, p. 1). Key to persona studies is exploring the construction of persona through participatory media use. Marshall proposes that creating a public persona is a task that is now increasingly common for greater and greater parts of the population (Marshall 2014, p. 154).

Marshall has also identified the movement from a primarily representational media environment to a primarily presentational media environment (Marshall [1997] 2014, p. xxxiixxxvi cited in Marshall 2015, p. 126). Representational media consists of "books, newspapers, magazines, film, radio and television" and has been considered dominant over the past two centuries. They are representational in that through "stories, narratives, and images, these media forms attempt to embody a populace" and represent a culture (Marshall 2014, p. 160). Presentational media, by contrast, is media that is "performed, produced and exhibited by the individual" outside of the representational media structure (Ibid.). As participatory media technologies become more and more a part of everyday life, so too does the act of constructing personas (Marshall 2015, p. 124).

Clearly, scholars in both participatory media studies and persona studies are concerned with the acts of cultural production occurring at the hands of participatory media users (Barbour, Marshall \& Moore 2014; Marshall 2015; Marshall and Barbour 2015; Marshall 2016). However, the Persona Studies perspective is interested in the idea that these acts of production involve constructing networked identities, each akin to wearing a different kind of mask. Studying participation through the lens of persona is to acknowledge that identity construction is part of participation in networked environments and vice versa. Barbour et al. cite Hannah Arendt's reading of persona in ancient Greece to note that "this mask of public identity was not seen in a derogatory way; rather it was natural to assume a public/political persona that was quite removed from the private and home sphere" (Arendt 1958 cited in Barbour, Marshall \& Moore 2014, p. 2). In other words, there was an expectation that individuals perform different personas in different settings.

Persona Studies places emphasis on the individual's inherent task of constructing identity through participation, considering it as an outcome alongside the emancipatory potentials of participatory cultures. It theoretically allows for the possibility of one individual having multiple personas, consisting of multiple dimensions (Moore, Barbour \& Lee 2017), which arguably better describes participatory media use in networked settings. Traditional media personalities may use podcasting to create communities, build bodies of collective intelligence and democratise the media landscape, but also because it allows them to grow their transmedia personal brands. This position thus recasts individual participation as an important economic task as well as a potentially social, cultural and political pursuit. Participation can therefore lead to the empowering potentials that Jenkins wrote of, but also feed into the commercial logics of traditional media hierarchies. As such, persona studies reveals concepts that can be used to insightfully describe the contemporary use of the podcast with nuances not currently considered in podcasting literature.

Kim Barbour has observed how variations in the performance of persona exist more broadly in networked environments. In her research on persona construction of street artists, tattooists, craftivists and performance poets, Barbour identified three registers of persona performance - professional, personal and intimate (Barbour 2015). The practicing of these various registers by individual artists revealed a process of selective self-presentation and the "capacity for agency in persona creation" (Ibid., p. 59). Persona registers enabled the subjects to retain some form of agency in experiences of tension that Barbour categorised as: strategy/happenstance, specialisation/diversification, visibility/self-protection, self/collective and work/play (Ibid., p. 61). For example, some of Barbour's subjects employed a professional 
persona register to engage in networked environments where visibility and self-protection were at odds. This involved revealing only certain aspects of their personalities online, which was effective in distancing the artists from their work where a degree of anonymity was needed - critical for street artists whose work is oftentimes deemed illegal (Ibid., p. 62). Barbour further observed, "The personal register of performance extends the artist's persona past that of artistness, and gives their audience of fans and followers insight into the personality and values of the person behind the work" (Ibid., p. 64). Additionally, artists observed employing an intimate register of persona did so to discuss life matters and moments not linked to their art practices, such as giving birth and taking drugs (Ibid., p. 67).

Barbour's typology provides media scholars with a lexicon to understand nuanced performance of persona across both traditional and DIY media networks, but also how these personal brands are constructed within single podcast episodes. It proposes that networked individuals have the ability to create discrete boundaries between these registers by strategically performing personas, but also offers clarity as to how these performances may operate in tandem. When applied to The Osher Günsberg Podcast Barbour's concept creates clarity for scholars but also for listeners, viewers and readers potentially helping them to identify what persona register is being employed and importantly, to ask why and to what effect.

These ideas from persona studies are not comprehensively considered in podcasting discourse within media studies. Standing literature predominantly subscribes to the rhetoric of participatory empowerment that stemmed from early media theories associated with Web 2.0 technologies. A persona studies approach has the potential to bring theories of strategic selfpresentation into conversation with these new media canons that now appear unable to adequately describe contemporary phenomena such as the trend of branded media personalities creating their own podcast shows. Importantly, a focus on the imperative to create a networked persona with professional, personal and intimate registers draws academic research into closer contact with commercial agendas being explored by high profile conferences like the ABC's OzPod event and will allow scholars to further explore exactly how an individual's brand is used to navigate a changing media landscape.

\section{ACKNOWLEDGEMENTS}

Thank you to Dr Margie Borschke in the Department of Media, Music, Communication and Cultural Studies at Macquarie University for her mentorship and supervision during the writing of this research paper.

\section{WORKS CITED}

ABC 2016a, OzPod 2016: Australian Podcast Conference / \#ozpod2016, Australian Broadcasting Corporation, retrieved 28 May 2017,<http://www.abc.net.au/radio/programs/ozpod/>.

-2016b, Audience Research - 2016, retrieved 28 May 2017, <http://www.abc.net.au/cm/lb/7890592/data/abc-ozpod-audience-researchdata.pdf $>$.

Barbour, K 2015, 'Registers of performance: negotiating the professional, personal and intimate in online persona creation', in H Savigny, E Thorsen, D Jackson \& J Alexander (eds.), Media, Margins and Popular Culture, UK, Palgrave Macmillan, pp. 57-69. 
Barbour, K, Marshall, P.D \& Moore, C 2014, 'Persona to persona studies'. M/C Journal, vol. 17, no. 3.

Berry, R 2006, 'Will the iPod kill the radio star? Profiling podcasting as radio', Convergence: The International Journal of Research into New Media Technologies, vol. 12, no. 2, pp. 143-162.

- 2015. 'A Golden Age of Podcasting? Evaluating Serial in the Context of Podcast Histories', Journal of Radio \& Audio Media, vol. 22, no. 2, pp. 170-178.

Bird, S. E 2011. 'Are we all produsers now? Convergence and media audience practices', Cultural Studies, vol. 25, no. 4-5, pp. 502-516.

Blatberg, E 2015. 'The second coming of podcasts, in 4 charts', DigidayUK, 9 March, retrieved 20 September 2017, <https://digiday.com/media/podcasts-5-chars/>.

Boggs, J 2017, Apple Podcasts WWDC17 - Session 512, The Apple Worldwide Developers Conference, retrieved 28 June 2017, $<$ https://developer.apple.com/videos/play/wwdc2017/512/>.

Borschke, M 2014, 'The new romantics: Authenticity, participation and the aesthetics of piracy', First Monday, vol. 19, no. 10.

Bottomley, A J 2015, 'Podcasting, Welcome to Night Vale, and the Revival of Radio Drama', Journal of Radio \& Audio Media, vol. 22, no. 2, pp. 179-189.

Bruns, A 2008, Blogs, Wikipedia, Second Life, and beyond: From production to produsage, (Vol. 45), New York, Peter Lang.

Bull, M 2006, 'No dead air! The iPod and the culture of mobile listening', Leisure studies, vol. 24 , no. 4 , pp. 343-355.

Crawford, K 2009, 'Following You: Disciplines of Listening in Social Media', Continuum, vol. 23, no. I4, pp. 525-535.

-2009, 'Listening as Participation: Social Media and Metaphors of Hearing Online', The Good, The Bad and The Challenging: The User and The Future of Information and Communication Technologies, COST 298 Conference Journal. Copenhagen: COST.

- 2012, 'Four ways of Listening to an iPhone: From Sound and Network Listening to Biometric Data and Geolocative Tracking', in L Hjorth, I Richardson \& J Burgess (eds.), Studying Mobile Media: Cultural Technologies, Mobile Communication, and the iPhone, London and New York, Routledge, pp. 213-239.

Crofts, S, Fox, M, Retsema, A and Williams, B 2005, 'Podcasting: A new technology in search of viable business models', First Monday, vol. 10, no. 9.

De Certeu, M 1984, The Practice of Everyday Life. Berkeley, University of California Press.

Dredge, S 2014. 'Serial podcast breaks iTunes records as it passes $5 \mathrm{~m}$ downloads and streams', The Guardian, 19 November, retrieved 20 September 2017, <https://www.theguardian.com/technology/2014/nov/18/serial-podcast-itunesapple-downloads-streams $>$.

Ep 143: Socratis Otto, podcast, Osher Günsberg, 25 July 2016, retrieved 4 September 2016 < https://podcasts.apple.com/ai/podcast/ep-143-socratisotto/id711028488?i=1000373016188>

Fauteux, B 2015, 'Blogging Satellite Radio: Podcasting Aesthetics and Sirius XMU's Blog Radio', Journal of Radio \& Audio Media, vol. 22, no. 2, pp. 200-208. 
Granitz, N \& Forman, H 2015, 'Building self-brand connections: Exploring brand stories through a transmedia perspective', Journal of Brand Management, vol. 22, no. 1, pp. 38-59.

Gregg, M \& Seigworth, G J (eds.) 2010. The affect theory reader. Durham, Duke University Press.

Hammersley, B 2004. 'Audible Revolution', Guardian Online, 12 February, retrieved 26 July 2016, <https://www.theguardian.com/media/2004/feb/12/broadcasting.digitalmedia $>$.

Harré, R 1979. Social Being: A Theory for Social Psychology. Oxford, Blackwell.

Hesmondhalgh, D \& Baker, S. 2010. Creative labour: Media work in three cultural industries. London, Routledge.

Jenkins, H 1992. Textual poachers: Television fans and participatory culture. London, Routledge.

- 2004. 'The cultural logic of media convergence'. International journal of cultural studies, vol. 71, pp. 33-43.

- 2006a. Convergence culture: Where old and new media collide. New York, New York University Press.

- 2006b. Fans, bloggers, and gamers: Exploring participatory culture. New York, New York University Press.

- 2007. 'Transmedia Storytelling 101', Confessions of an Aca-Fan, 21 March, retrieved 27 July 2016, <http://henryjenkins.org/2007/03/transmedia_storytelling_101.html>.

- 2014. 'Rethinking 'rethinking convergence/culture". Cultural Studies, vol. 28, no. 2, pp. 267-297.

Jenkins, H, Ford, S \& Green, J 2013. Spreadable media: creating value and meaning in a networked culture. New York, New York University Press.

Jenkins, H, Purushotma, R, Weigel, M, Clinton, K \& Robison, A 2009. Confronting the challenges of participatory culture: Media education for the 21st century. Cambridge, MIT Press.

Leadbeater, C \& Miller, P 2004. The Pro-Am Revolution, London, Demos.

Lévy, P 1997. Collective intelligence: mankind's emerging world in cyberspace. New York, Plenum/Harper Collins.

Lindgren, M \& McHugh, S A 2013. 'Not dead yet: Emerging trends in radio documentary forms in Australia and the US', Australian Journalism Review, vol. 35, no. 2, pp. 101113.

MacDougall, R C 2011. 'Podcasting and political life'. American Behavioral Scientist, vol. 55, no. 6, pp. 714-732.

Madsen, V 2009. 'Voices-cast: a report on the new audiosphere of podcasting with specific insights for public broadcasting', ANZCA09 Communication, Creativity and Global Citizenship pp. 1191-1207, < https://researchmanagement.mq.edu.au/ws/portalfiles/portal/17154626/mq-16890Publisher+version+\%28open+access\%29.pdf>. 
Madsen, V \& Potts, J 2010, 'Voice-Cast: the distribution of the voice via podcasting', in N Neumark, R Gibson \& T van Leeuwin (eds.), Voice: vocal aesthetics in digital arts and media. Cambridge Mass., MIT Press, pp. 33-59.

Markman, K M 2011. 'Doing radio, making friends, and having fun: Exploring the motivations of independent audio podcasters.' New Media \& Society, vol. 14, no. 4, pp. 547-565.

Marshall, P D [1997] 2014. Celebrity and power: Fame in contemporary culture. Minneapolis, University of Minnesota Press.

- 2014. 'Persona studies: Mapping the proliferation often the public self', Journalism, vol. 15, no. 2, pp. 153-170.

- 2015. 'Monitoring persona: mediatized identity and the edited public self'. Frame: Journal of Literary Studies, vol. 28, no. 1, pp. 115-133.

- 2016. The Celebrity Persona Pandemic. Minneapolis, University of Minnesota Press

Marshall, P D \& Barbour, K 2015. 'Making intellectual room for persona studies: a new consciousness and a shifted perspective', Persona Studies, vol. 1, no.1, pp. 1-12.

McClung, S \& Johnson, K 2010. 'Examining the motives of podcast users'. Journal of Radio \& Audio Media, vol. 17, pp. 82-95.

McHugh, S 2012. 'The affective power of sound: oral history on radio'. The Oral History Review, vol. 39, no. 2, pp. 187-206.

- - 2016. 'How podcasting is changing the audio storytelling genre'. Radio Journal: International Studies in Broadcast \& Audio Media, vol. 14, no. 1, pp. 65-82.

McKee, A 2003. Textual analysis: A beginner's guide, London, Sage.

Menduni, E 2007. 'Four steps in innovative radio broadcasting: From QuickTime to podcasting', Radio Journal: International Studies in Broadcast \& Audio Media, vol. 5, no. 1, pp. 9-18.

Meserko, V M 2014. 'Going Mental: Podcasting, Authenticity, and Artist-Fan Identification on Paul Gilmartin's Mental Illness Happy Hour', Journal of Broadcasting \& Electronic Media, vol. 58, no. 3, pp. 456-469.

- 2015a. 'Standing Upright: Podcasting, Performance, and Alternative Comedy', Studies in American Humor, vol. 1, no. 1, pp. 20-40.

- 2015b. 'The pursuit of authenticity on Marc Maron's WTF podcast', Continuum, vol. 29, no. 6, pp. 796-810.

Micelo D \& Domkis D, 2017. 'Homepage', The Dawn and Drew Show, retrieved 17 September 2019, <http://thedawnanddrewshow.com $>$.

Moore, C, Barbour, K \& Lee, K 2017. 'Five dimensions of online persona', Persona Studies, vol. 3, no. 1, pp. 1-11

Morris, J.W. \& Patterson, E 2015. 'Podcasting and its Apps: Software, Sound, and the Interfaces of Digital Audio', Journal of Radio \& Audio Media, vol. 22, no. 2, pp. 220-230.

Murray, S 2009.' Servicing 'self-scheduling consumers' Public broadcasters and audio podcasting', Global Media and Communication, vol. 5, no. 2, pp. 197-219.

Oktay, J S 2012. Grounded theory. New York, Oxford University Press. 
Please support the podcast $x$, YouTube 2016, Osher Günsberg, 12 February, retrieved 26 July 2016 <https://www.patreon.com/osher>.

Price Waterhouse Coopers, 2018. IAB Podcast Ad Revenue Study: An Analysis of the Largest Players in the Podcasting Industry, retrieved 24 April 2019,

$<$ https://www.iab.com/wpcontent/uploads/2018/06/2018 IAB Podcast Ad Rev Study vFinal.pdf>

Roose, K 2014. 'What's behind the great podcast renaissance', New York Magazine, 30 October, retrieved 15 September 2017, $<$ http://nymag.com/daily/intelligencer/2014/10/whats-behind-the-great-podcastrenaissance.html $>$.

Spinelli, M \& Dann, L 2018. Podcasting: the audio media revolution. New York, Bloomsbury Academic.

Toffler, A 1980. The Third Wave. New York: Bantam books.

Tulley, C 2011. 'IText reconfigured: The rise of the podcast', Journal of Business and Technical Communication, vol. 25, no. 3, pp. 256-275. 